\title{
Limitation of Use Based on Duration of Use
}

National Cancer Institute

\section{Source}

National Cancer Institute. Limitation of Use Based on Duration of Use. NCI Thesaurus.

Code C60655.

A restriction on the use of a device, medicine or treatment based on time limit parameters set forth by the approver. 